\title{
Study the Synthesis Parameter of Tin Oxide
}

\section{Nanostructure}

\author{
Gyanendra Prakash Shukla and Mukesh Chandra Bhatnagar* \\ Physics Department, Indian Institute of Technology, New Delhi 110016, Indian
}

\begin{abstract}
In this article, the effect of synthesis parameters on structural properties of $\mathrm{SnO}_{2}$ nanowire by thermal evaporation process, have been studied. The nanostructures are characterized by scanning electron microscopy, Transmission electron microscopy and $\mathrm{X}$-ray spectroscopy. By X-ray diffraction pattern, synthesized $\mathrm{SnO}_{2}$ nanowire were found to be crystalline rutile $\mathrm{SnO}_{2}$. We studied the effect of synthesis parameters such as the deposition temperature, distance variation of the substrate from precursor on the structure of our synthesized nanowires. It was found that their growth was governed by vapor-liquid-solid mechanism (VLS) because of using Sn self catalyst. In this mechanism, the Sn droplet deposited serve as preferred sites for the growth of $\mathrm{SnO}_{2}$ nanowire.
\end{abstract}

Key words: Tin oxide NWs, thermal evaporation, synthesis factor.

\section{Introduction}

Transparent conducting and semiconducting oxide nonmaterial like tin oxide have [1] variety of practical application such as light emitting diode [1], solar cell [2] and sensor [3]. These nanostructures can be grown by various methods such as thermal treatment [6], hydrothermal method [8] and electrochemical deposition [7] and thermal evaporation. We have synthesized tin oxide nanostructure by one of simplest method named as thermal evaporation. In thermal evaporation process, researcher are using most common process name carbothermal reducing process $[4,5]$ by which we can deposited material at some lower temperature respect to desired melting point of that metal oxide material. In the study of Wu et al. [11] in 2005, the influence of reaction on the temperature of synthesis at $850{ }^{\circ} \mathrm{C}$ elucidated. They also considered the effect of the temperature of synthesis on the reaction time of $1 \mathrm{~h}$ on the structure of $\mathrm{TiO}_{2}$ nanowires [12]. By these consideration, variation in growth parameter, like temperature, gas flow rate and distance of substrate to source, the morphology of deposited nanostructure can be modify. In growth of

*Corresponding author: Mukesh Chandra Bhatnagar, associate professor, research field: chemical sensor. metal oxide, there is many reported work for metal oxide to carbon (graphite) ratio in was taken in decade years. That's why; researcher had taken most common ratio 1:1 of tin oxide material with graphite powder. Tin oxide, nanostructures using the mixture of the corresponding oxide (tin oxide) material and graphite in 1:1 ratio as the source material. The Effect of the growth temperature and source to precursor distance variation on the morphology and properties of the obtained nanomaterials had been studied.

\section{Experiment}

A commercial one surface polished n-type Si (100) oriented $50 \mathrm{~mm}$ in diameter wafer with resistivity 1-20 $\Omega$-inch and thickness $525 \pm 25 \mu \mathrm{m}$ was used as a substrate and source of silicon for the growth of $\mathrm{SnO}_{2} / \mathrm{Si}$ nanostructure. The $\mathrm{Si}$ wafer was cut into dimensions of 0.5 inch $\times 0.5$ inch before being cleaned by standard RCA cleaning method. Alumina boat, on which deposition has been taken, cleaned with propanol along with acetone. I have taken $\mathrm{SnO}_{2}$ powder ( $99.99 \%$ pure) along with graphite fine powder $(99.50 \%$ pure) in 1:1 ratio as a precursor. Ar gas had taken at constant flow rate of $100 \mathrm{sccm}$. Prior of heating, pressure inside the furnace keeps on 
atmosphere pressure. Furnace was heated up to $900^{\circ} \mathrm{C}$, $1,000{ }^{\circ} \mathrm{C}$ and $1,100{ }^{\circ} \mathrm{C}$ to analysis the temperature effect in growth of nanostructure. Deposition was maintained till $1 \mathrm{~h}$. The set up of atmospheric sintering furnace is shown on Fig. 1.

\section{Characterization of Nanostructure}

A set of five nanostructure samples has been prepared with different growth conditions of tin oxide. Table 1 shows the details of prepared sample.

Nanostructure obtained by synthesis was subjected to characterization by XRD (X-ray diffraction), SEM (Scanning electron microscopy), TEM (Transmission electron microscopy) and UV-Vis reflection spectra. Crystal structure can be understood by X-ray diffraction peaks which clearly shown tetragonal structure of tin oxide. The crystallite size $(\mathrm{t})$ was calculated from the FWHM (Full width at half maximum) of the maximum intense diffraction peak of the XRD pattern by using the Debye-Scherrer formula [9] given by:

$$
\mathrm{t}=0.9 \lambda / \beta \cos \theta
$$

where, $\lambda$ is the wavelength of the X-rays used, $\beta$ is the FWHM, $\theta$ is the Bragg angle, and $t$ is the average crystallite size. From above equation, crystalline size of $\mathrm{SnO}_{2}$ nanostructure have been found $51 \mathrm{~nm}, 91 \mathrm{~nm}$ and $269 \mathrm{~nm}$ for substrate at $50 \mathrm{~mm}, 75 \mathrm{~mm}$ and $25 \mathrm{~mm}$ respectively at $1,100{ }^{\circ} \mathrm{C}$ as probability of precipitation of $\mathrm{SnO}$ vapour in $\mathrm{Sn}$ metal droplet is higher as we far from precursor. Again $1693 \mathrm{~nm}$ and $4 \mathrm{~nm}$ for $1,000{ }^{\circ} \mathrm{C}$ and $900^{\circ} \mathrm{C}$ respectively at $50 \mathrm{~mm}$ from source, it is only due to desired melting temperature at near to $1,100^{\circ} \mathrm{C}$. Fig. 2 shows the XRD patterns of the tin oxide nanostructure at variety in synthesis parameter. The products are crystalline and the diffraction peaks can be indexed as the tetragonal rutile structure, which is consistent with the reported data (JCPDS).

Now surface morphology was investigated by SEM and SEM image shows the growth of tin oxide nanostructure on Si substrate. Observed diameter of nanostructure on substrate at $25 \mathrm{~mm}, 50 \mathrm{~mm}$ and 75 $\mathrm{mm}$ were $450 \mathrm{~nm}, 250 \mathrm{~nm}$ and $50 \mathrm{~nm}$ respectively and length of nanowire was found approximately several microns. Again diameter at substrate at different deposition temperature $1,000{ }^{\circ} \mathrm{C}$ was $400 \mathrm{~nm}$ with length approximately several microns. Substrate at $900{ }^{\circ} \mathrm{C}$ was not supported due to very low vaporising temperature for $\mathrm{SnO}$ respect to desired temperature. The diameter of nanowire corresponding to varying synthesis parameter is shown in Fig. 3.

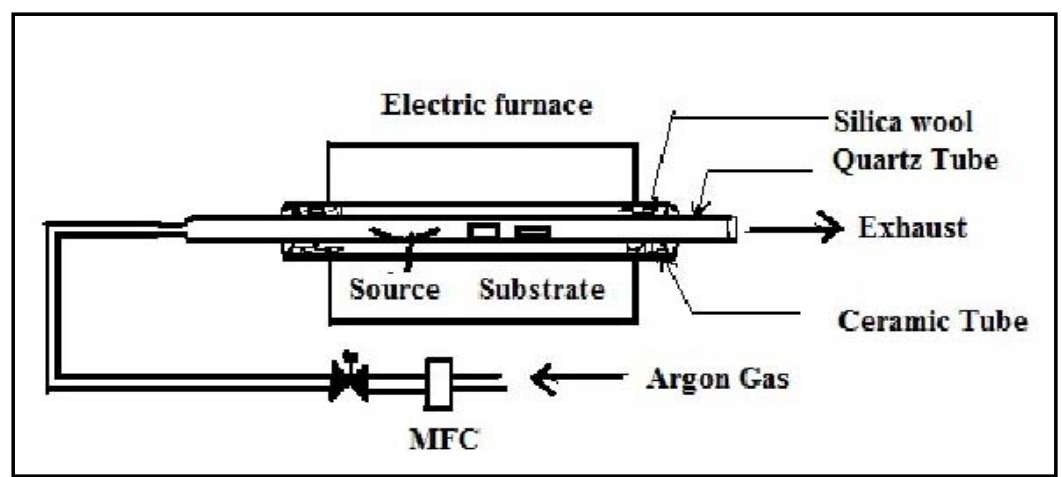

Fig. 1 Schematic diagram of thermal evaporation chamber.

Table 1 Nomenclature of $\mathrm{SnO}_{2}$ samples when substrate placed at “atm" pressure.

\begin{tabular}{ll}
\hline Sample details & Aberrations as referred in text \\
\hline $25 \mathrm{~mm}$ from source at $1,100^{\circ} \mathrm{C}, 100 \mathrm{sccm}$ & $\mathrm{Sn} 1$ \\
$50 \mathrm{~mm}$ from source at $1,100{ }^{\circ} \mathrm{C}, 100 \mathrm{sccm}$ & $\mathrm{Sn} 2$ \\
$75 \mathrm{~mm}$ from source at $1,100^{\circ} \mathrm{C}, 100 \mathrm{sccm}$ & $\mathrm{Sn} 3$ \\
$50 \mathrm{~mm}$ from source at $1,000^{\circ} \mathrm{C}, 100 \mathrm{sccm}$ & $\mathrm{Sn} 4$ \\
$50 \mathrm{~mm}$ from source at $900{ }^{\circ} \mathrm{C}, 100 \mathrm{sccm}$ & $\mathrm{Sn} 5$ \\
\hline
\end{tabular}




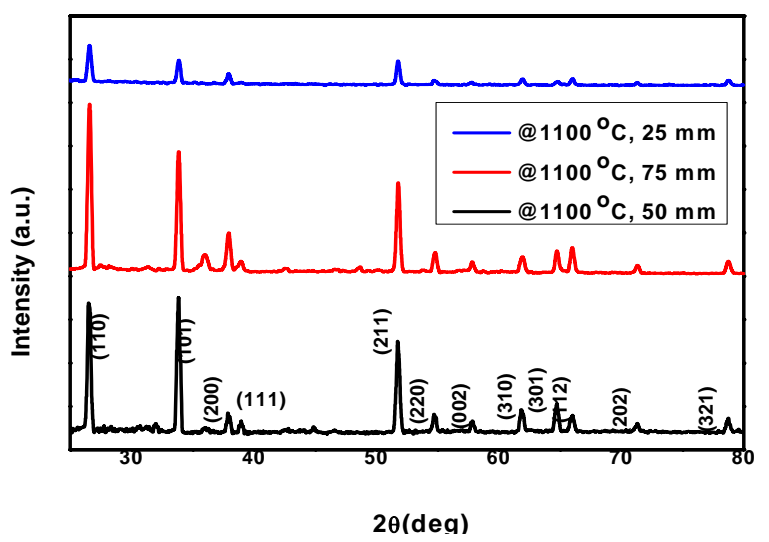

(a)

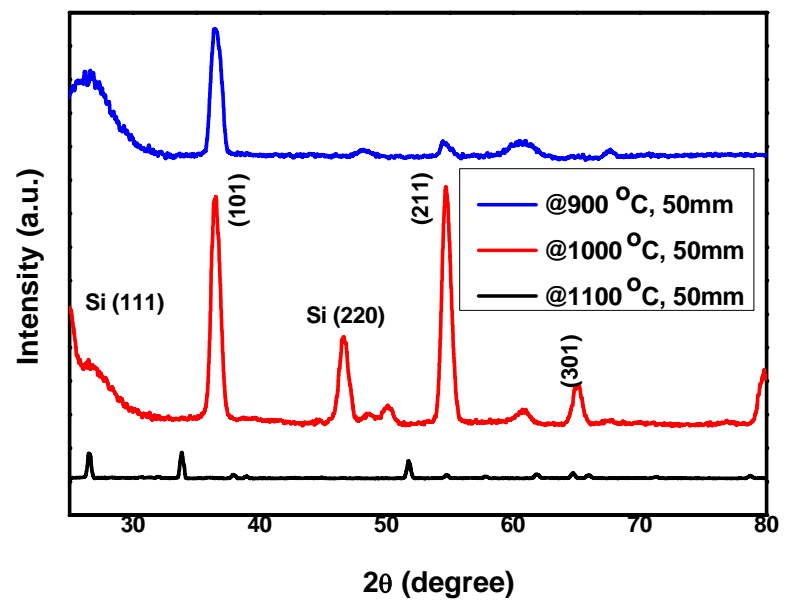

(b)

Fig. 2 XRD image of tin oxide nanostructure at variation in: (a) distance between source to substrate shows tetragonal structure and (b) synthesis temperature shows tetragonal structure.

Now as we know that melting temperature of $\mathrm{SnO}_{2}$ powder is $1,630^{\circ} \mathrm{C}$, but after carbothermal process, it can be reduced till $1,100{ }^{\circ} \mathrm{C}$ so we can see that possible growth of nanostructure at $1,100{ }^{\circ} \mathrm{C}$. Now VLS growth mechanism for growth of nanostructure can understand by TEM image shown in Fig. 4. Schmatic diagram of growth of nanowire have been shown in Fig. 5.

From the theory of thermal physics or thermodynamically it was clear that high pressure can cause reduction in melting temperature of the material. So pressure inside the quartz tube was an important parameter but by physics atmospheric pressure. A model has been discussed for all kind of growth condition inside thermal evaporation chamber is shown in Fig. 6. Table 3 shows combine study along result observed by varying various parameters for growth of tin oxide nanostructure.

Discussion can carried out some more explanation towards justification for above experiment.

We can now solve for the velocity of the SnO molecules at any temperature by formula:

$$
\begin{gathered}
(1 / 2) \mathrm{mv}^{2}=(3 / 2) \mathrm{kT} \\
\mathrm{mv}^{2}=3 \mathrm{kT} \\
\mathrm{v}^{2}=3 \mathrm{kT} / \mathrm{m}
\end{gathered}
$$

where, $\mathrm{m}$ is mass, $\mathrm{v}$ is velocity, $\mathrm{k}$ is Boltzmann's constant, and $\mathrm{T}$ is the temperature in Kelvin. Now calculated root means square velocity of $\mathrm{SnO}$ vapour at $1100{ }^{\circ} \mathrm{C}$ is $50.417 \mathrm{~cm} / \mathrm{s}$ from above equation. $\mathrm{T}$ rue mass flow of Ar gas can be calculated from Standard cubic centimetres per minute ( $\mathrm{sccm}$ ) by equation.

$$
\mathrm{m}=(\mathrm{mP} / \mathrm{nRT}) \mathrm{Q}
$$




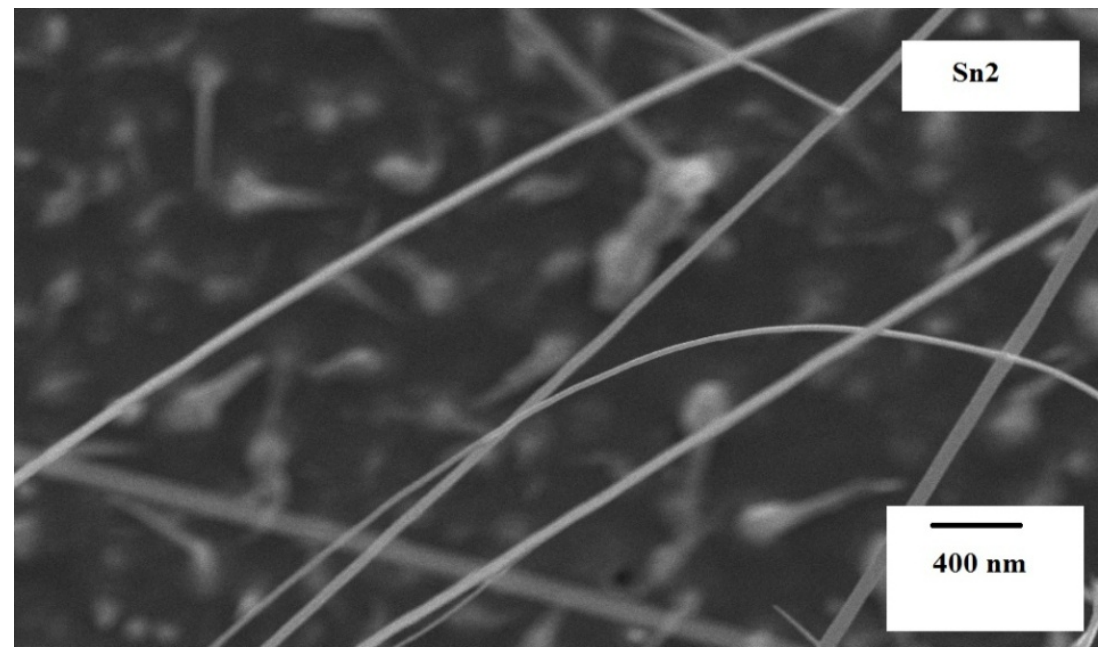

(a)

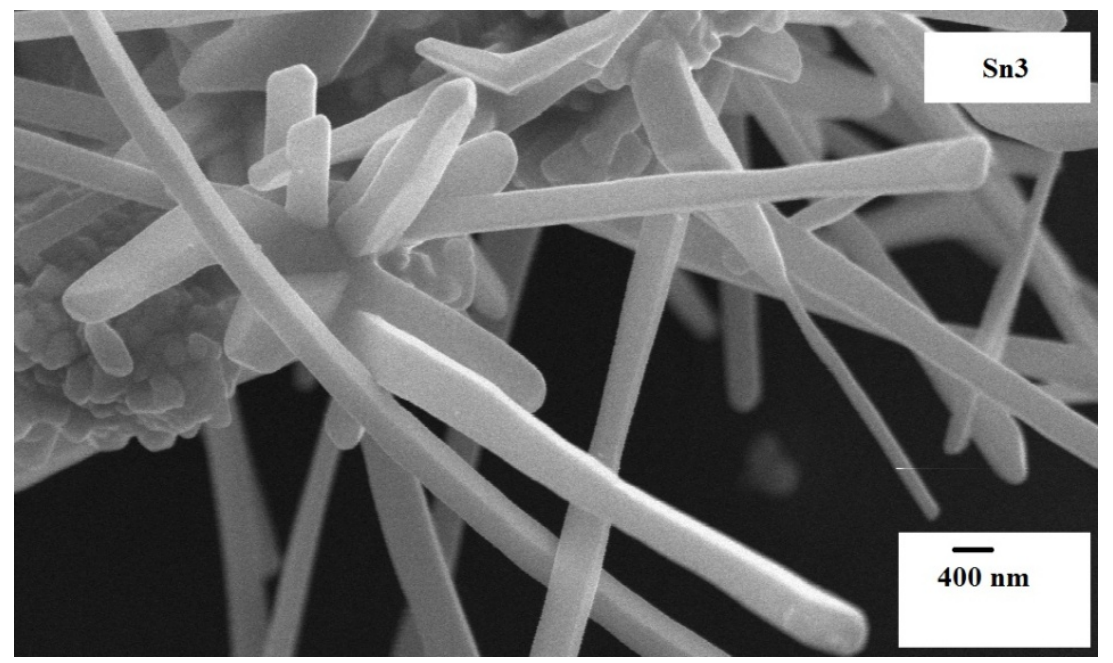

(b)

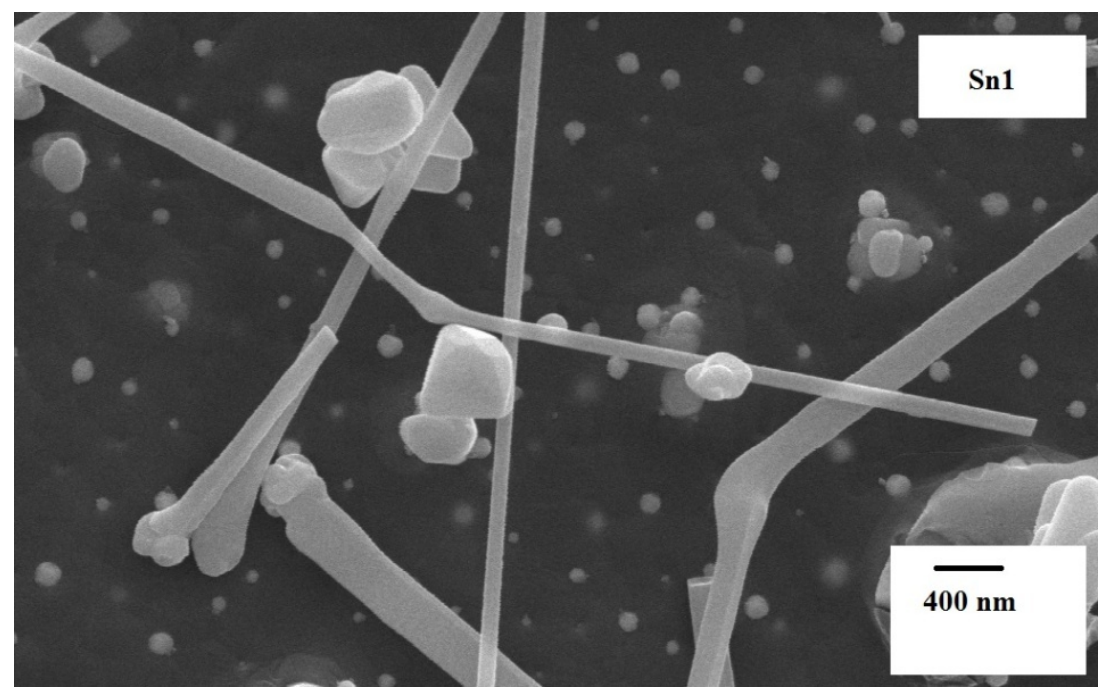

(c) 


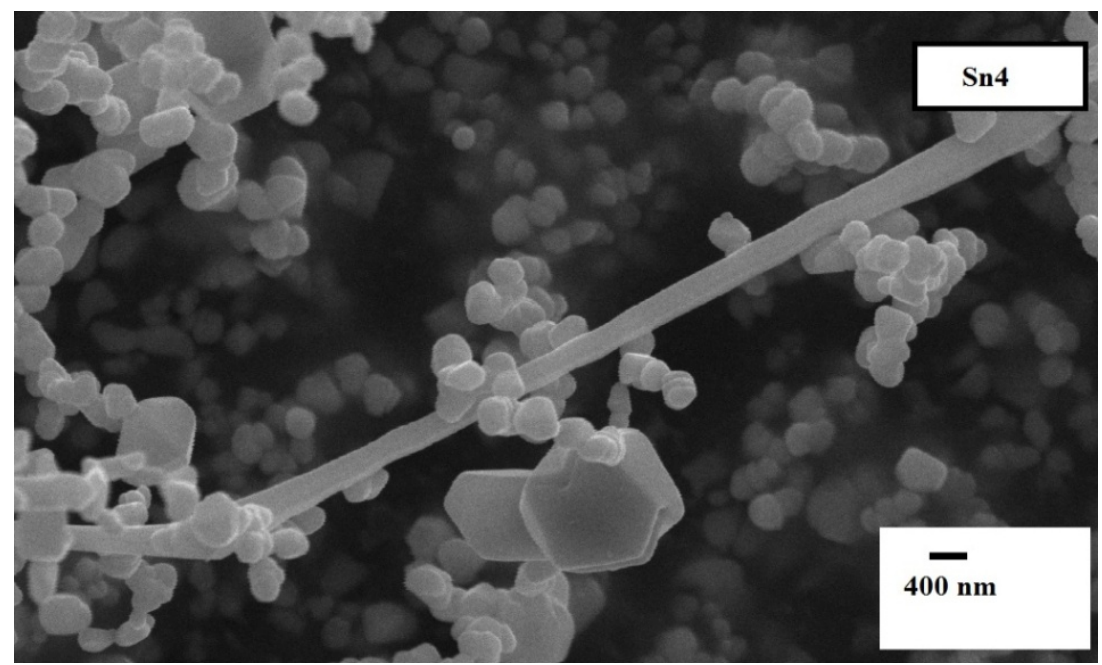

(d)

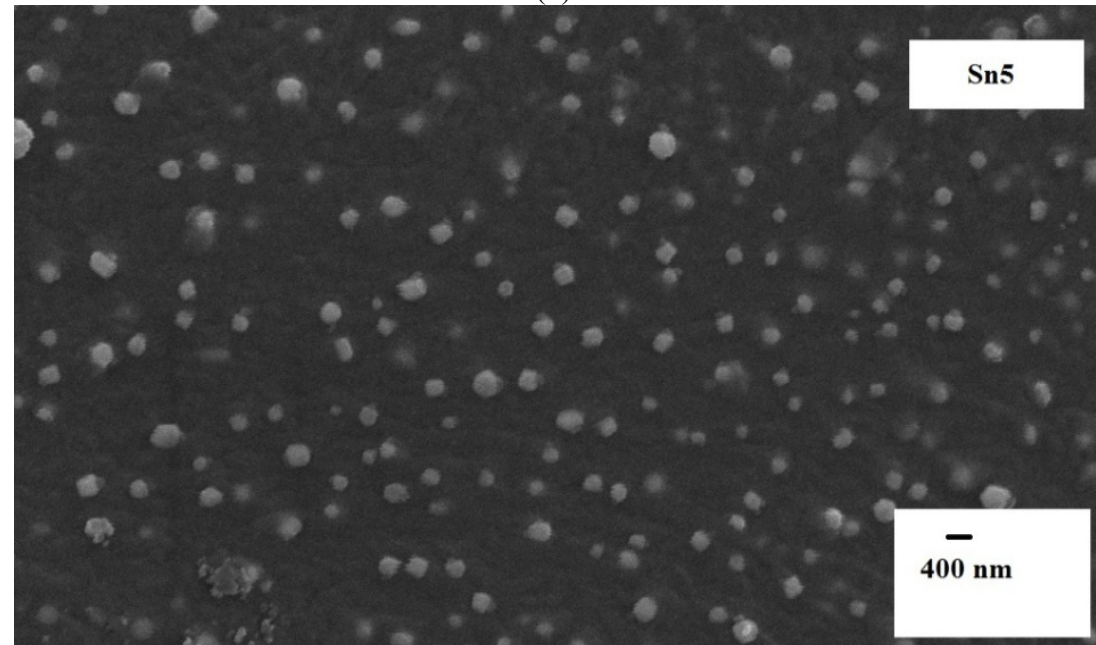

(e)

Fig. 3 SEM image of tin oxide nanostructure shows diameter approx: (a) $50 \mathrm{~nm}$ at 1,100 ${ }^{\circ} \mathrm{C}, 50 \mathrm{~mm}$ and $100 \mathrm{sccm}$ flow rate; (b) $200 \mathrm{~nm}$ to $300 \mathrm{~nm}$ at $1,100{ }^{\circ} \mathrm{C}, 75 \mathrm{~mm}$ and $100 \mathrm{sccm}$ flow rate; (c) $400 \mathrm{~nm}$ to $600 \mathrm{~nm}$ at 1,100 $\mathrm{C}, 25 \mathrm{~mm}$ and $100 \mathrm{sccm}$ flow rate: (d) $400 \mathrm{~nm}$ at $1,000{ }^{\circ} \mathrm{C}, 50 \mathrm{~mm}$ and $100 \mathrm{sccm}$ flow rate; (e) at $900{ }^{\circ} \mathrm{C}, 50 \mathrm{~mm}$ and $100 \mathrm{sccm}$ flow rate.

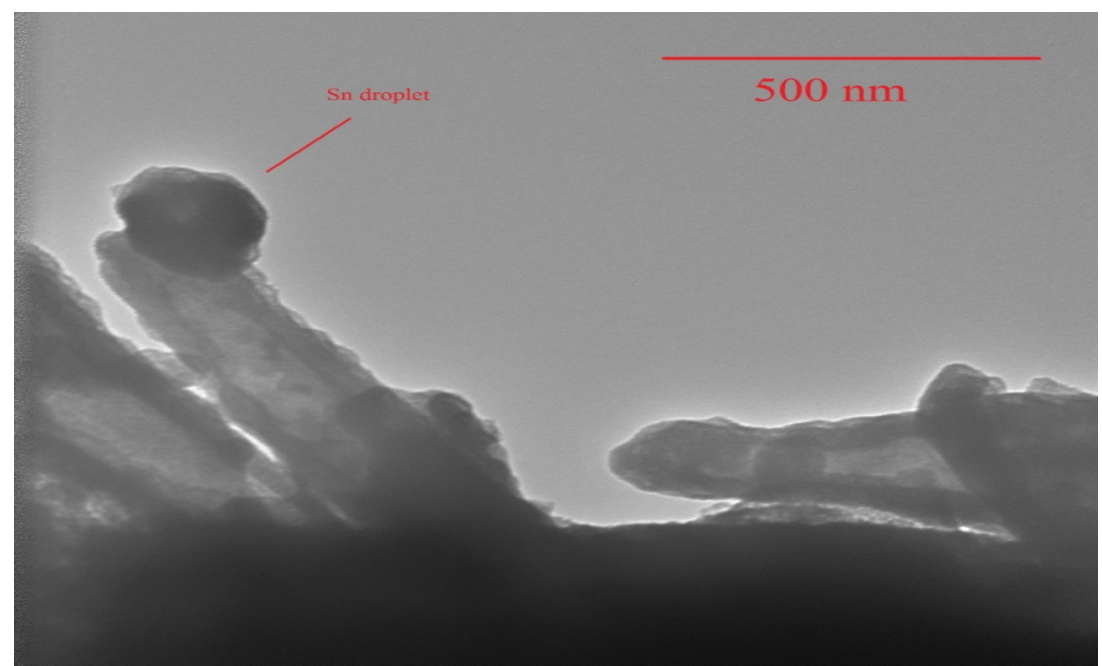

Fig. 4 TEM image shows VLS growth of self catalyse Sn droplet on the tip of nanostructure observed at $1,100{ }^{\circ} \mathrm{C}$ at $50 \mathrm{~mm}$ from source. 
Table 2 Synthesis condition and morphology of $\mathrm{SnO}_{2}$ nanowire at “atm” pressure.

\begin{tabular}{llllll}
\hline $\begin{array}{l}\text { Furnace centre } \\
\text { temperature }\left({ }^{\circ} \mathrm{C}\right)\end{array}$ & $\begin{array}{l}\text { Carrier gas } \\
\text { flow }(\mathrm{sccm})\end{array}$ & Deposition time $(\mathrm{h})$ & $\begin{array}{l}\text { Distance from source Diameter of } \\
(\text { inch })\end{array}$ & $\begin{array}{l}\text { Length of nanowire } \\
\text { nanowire }(\mathrm{nm})\end{array}$ \\
\hline $1,100^{\circ} \mathrm{C}$ & 100 & 1 & 1 & 450 & 10 \\
$1,100^{\circ} \mathrm{C}$ & 100 & 1 & 2 & 50 & 30 \\
$1,100{ }^{\circ} \mathrm{C}$ & 100 & 1 & 3 & 250 & 20 \\
$1,000^{\circ} \mathrm{C}$ & 100 & 1 & 2 & 400 & 22 \\
$900{ }^{\circ} \mathrm{C}$ & 100 & 1 & 2 & - & - \\
\hline
\end{tabular}

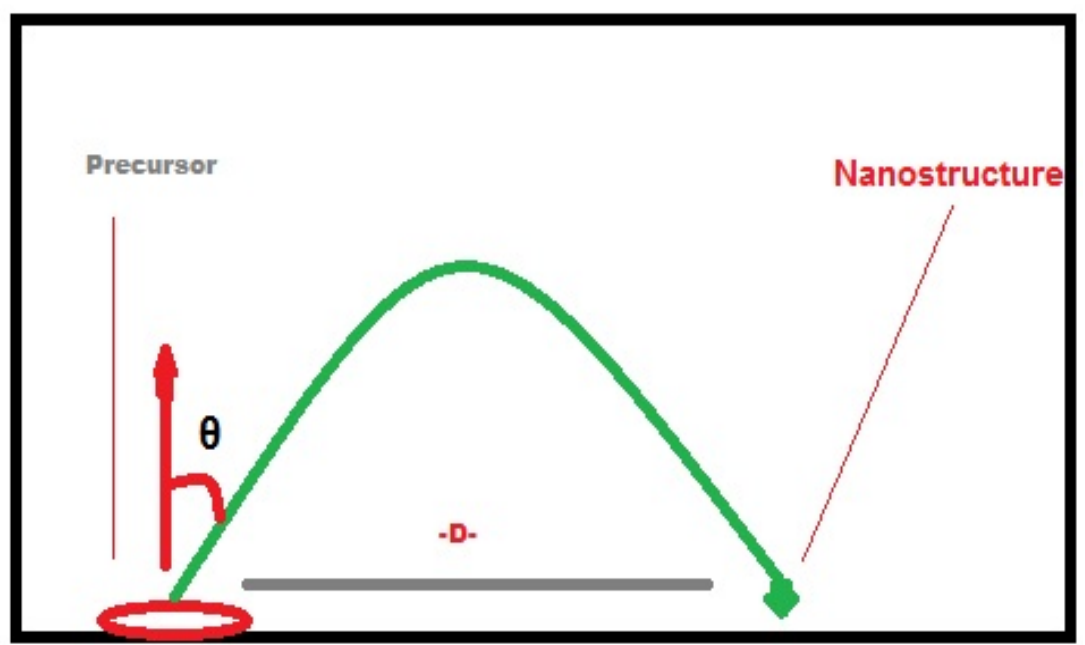

Fig. 5 Schematic diagram of projectile motion of $\mathrm{SnO}$ vapour.

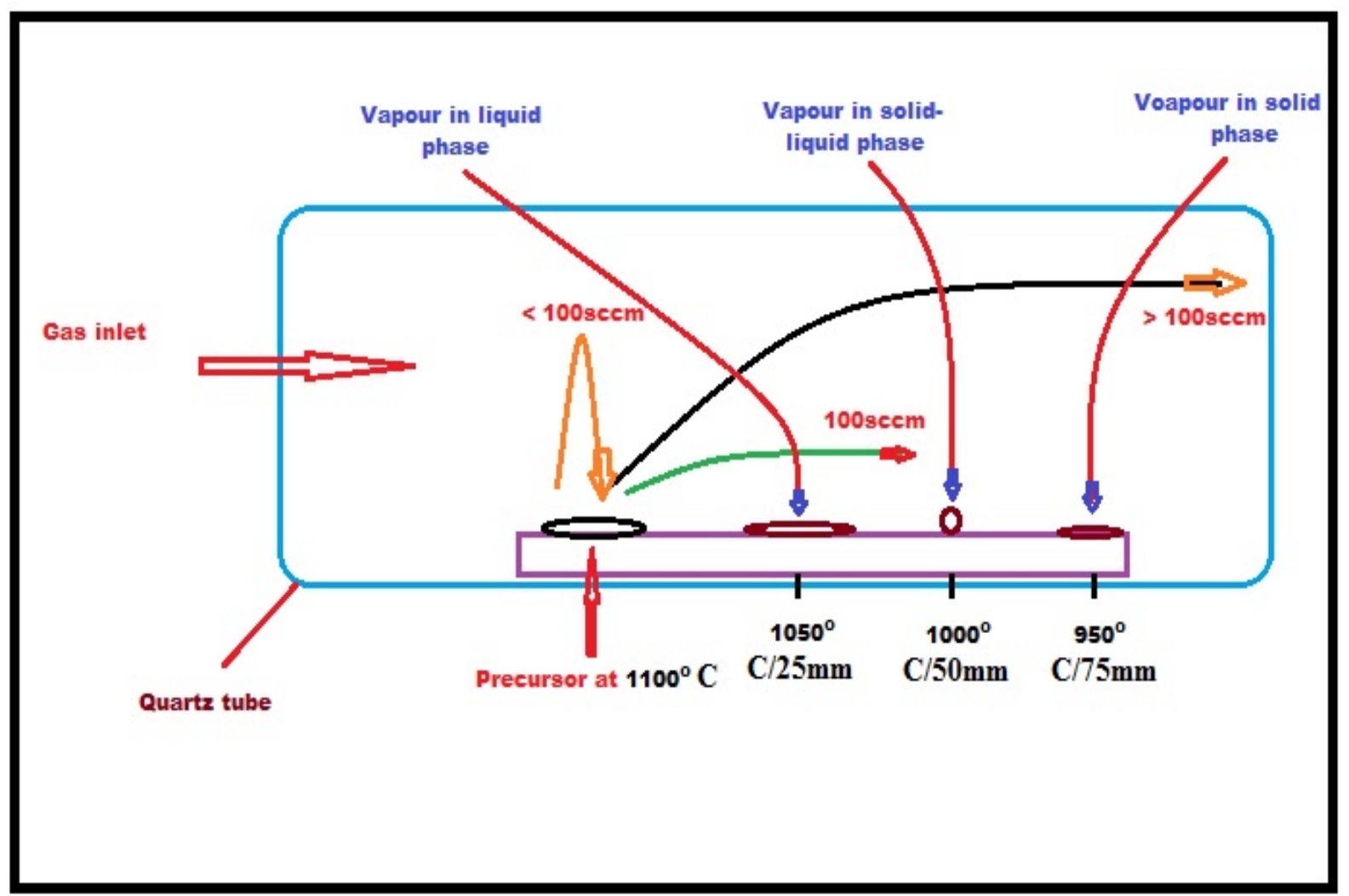

Fig. 6 Growth model of tin oxide nanostructure by varying synthesis parameter. 
Table 3 Outcome by varying synthesis parameters in the growth of tin oxide nanostructure.

\begin{tabular}{ll}
\hline Sample name & Experimental observation \\
\hline $\mathrm{SnO}_{2}$ placed $25 \mathrm{~mm}$ from source at $1,100^{\circ} \mathrm{C}, 100 \mathrm{sccm}(\mathrm{Sn} 1)$ & $\begin{array}{l}\text { Nanostructure observe with much high diameter was not helpful gas } \\
\text { sensing application }\end{array}$ \\
$\mathrm{SnO}_{2}$ placed $50 \mathrm{~mm}$ from source at $1,100^{\circ} \mathrm{C}, 100 \mathrm{sccm}(\mathrm{Sn} 2)$ & $\begin{array}{l}\text { Nanostructure observe with narrow diameter (high aspect ratio) was } \\
\text { suitable gas sensing application }\end{array}$ \\
$\mathrm{SnO}_{2}$ placed $75 \mathrm{~mm}$ from source at $1,100^{\circ} \mathrm{C}, 100 \mathrm{sccm}(\mathrm{Sn} 3)$ & $\begin{array}{l}\text { Nanotube observe with much diameter was not helpful gas sensing } \\
\text { application }\end{array}$ \\
$\mathrm{SnO}_{2}$ placed $50 \mathrm{~mm}$ from source at $1,000{ }^{\circ} \mathrm{C}, 100 \mathrm{sccm}(\mathrm{Sn} 4)$ & $\begin{array}{l}\text { Nanoparticles were observed. } \\
\mathrm{SnO}_{2} \text { placed } 50 \mathrm{~mm} \text { from source at } 900{ }^{\circ} \mathrm{C}, 100 \mathrm{sccm}(\mathrm{Sn} 5)\end{array}$ \\
$\mathrm{SnO}_{2}$ placed $50 \mathrm{~mm}$ from source at $1,1000^{\circ} \mathrm{C}, 200 \mathrm{sccm}(\mathrm{Sn} 6)$ & Nothing wave dimension of microns \\
\hline
\end{tabular}

where, $\mathrm{P}=$ Pressure, $\mathrm{V}=$ Volume $\left(\mathrm{cm}^{3}\right), \mathrm{n}=$ Number of moles of gas $\mathrm{R}=$ Gas constant $(0.0821)(\mathrm{L} \cdot \mathrm{atm} / \mathrm{mol} \cdot \mathrm{K})$ or $82.1\left(\mathrm{~cm}^{3} \cdot \mathrm{atm} / \mathrm{mol} \cdot \mathrm{K}\right), \mathrm{T}=$ Absolute temperature in Kelvin $(\mathrm{K}), \mathrm{m}=$ Mass in grams $(\mathrm{g}), \mathrm{m}=$ Mass flow $(\mathrm{g} / \mathrm{min}), \mathrm{m}=$ Mass flow $(\mathrm{g} / \mathrm{min})$, and $\mathrm{Q}=$ Volumetric flow at standard conditions (SCCM). From these equations we can calculate mass flow of Ar gas from sccm scale which is equal to $0.000591 \mathrm{gram} / \mathrm{sec}$ at 100 $\mathrm{sccm}$ and $0.001182 \mathrm{grame} / \mathrm{s}$ at $200 \mathrm{sccm}$ concentration rate of the gas respectively, inside the thermal evaporation chamber. Now again Maximum Projectile Range expression for projectile range using the formula:

$$
\mathrm{D}=\mathrm{v}^{2} / \mathrm{g} \cdot \sin (2 \theta)
$$

Let the projectile start with a speed of $\mathrm{v}$, and angle $\theta$ with the horizontal surface. After some time $t$, it strikes the ground at a distance of $\mathrm{D}$. The value of $\mathrm{D}$ gives the range of the projectile motion. Fig. 6 shows schematic diagram of projectile motion of $\mathrm{SnO}$ vapour. Now, if suppose that mass flow of Ar gas as a velocity component and taken an resultant with $\mathrm{SnO}$ vapour velocity component at $100 \mathrm{sccm}$ concentration of gas by choosing that $\mathrm{SnO}$ vapour starts projectile motion with an angle $45^{\circ}$.

D was calculated approximate $5.09 \mathrm{~cm}$ from the precursor which is nearly satisfactory equal to our observation. If, the projectile angle can be taken as $30{ }^{\circ} \mathrm{C}$ and $80{ }^{\circ} \mathrm{C}$ (approximately assumed) when the concentration of gas was taken $200 \mathrm{sccm}$ and $80 \mathrm{sccm}$ respectively then D was approximately $7.68 \mathrm{~cm}$ and 2.8 $\mathrm{cm}$ respectively, from precursor which again good agreement with result.

\section{Conclusions}

The outcome of this study is that there are certain parameters for the synthesis and growth of nanostructures inside the thermal evaporation chamber at which the nanostructures can nucleate and grow. It has been observed that the most favorable place for the enhanced growth inside the thermal evaporation chamber is about $50 \mathrm{~mm}$ from precursor when the precursor temperature of $1,100{ }^{\circ} \mathrm{C}$ in case of tin oxide) and $100 \mathrm{sccm}$ Argon gas flow rate. In our experiment, it has been observed that substrate kept at $50 \mathrm{~mm}$ from precursor is the most suitable place for perfect nucleation. Gas flow rate also influence significantly and at higher flow rate, more than $100 \mathrm{sccm}$, the gas flow causes condensation of vapour on substrate before start precipitation, so no nucleation of nanostructures.

\section{Acknowledgement}

We acknowledge the financial support from CSIR grant 086(0954)/09/EMR-I.

\section{References}

[1] O'Dwyer, C., Szachowicz, M., Visimberga, G., Lavayen, V., Newcomb, S. B. and Torres, C. M. S. 2009. "Bottom-Up Growth of Fully Transparent Contact Layers of Indium Tin Oxide Nanowires for Light-Emitting Devices." Nat. Nanotechnol 4: 244.

[2] Fung, M. K., Sun, Y. C., Ng, A., Ng, A. M. C., Djurisic, A. B. and Chan, H. T. et al. 2011. "Indium Tin Oxide Nanorod Electrodes for Polymer Photovoltaics." ACS Appl. Mater. Interfaces 3: 527.

[3] Chen, X.-P., Wong, C. K. Y., Yuan, C. A. and Zhang, G.-Q. 2013. "Nanowire-Based Gas Sensors." Sensors and Actuators B 177: 178-95

[4] Park, J.-H., Choi, H,-J. and Park, J.-G. 2004. Journal of 
the Korean Physical Society 45 (3): 729-32.

[5] Salehi, M., Janfeshan, B. and Sadrnezhaad, S. K. 2009. "Growth of Tin Oxide Nanotubes by Aerial Carbothermal Evaporation.” Appl. Phys. A 97: 364.

[6] Shih, P.-H., Hung, H.-J., Ma, Y.-R. and Wu, S.-Y. 2012. "Tuning the Dimensionality of $\mathrm{ZnO}$ Nanowires through Thermal Treatment: An Investigation of Growth Mechanism.” Nanoscale Research Letters 7: 354.

[7] Kovtyukhova, N. I. and Mallouk, T. E. 2011. "Conductive Indiumetin Oxide Nanowire and Nanotube Arrays Made by Electrochemically Assisted Deposition in Template Membranes: Switching Between Wire and Tube Growth Modes by Surface Chemical Modification of the Template." Nanoscale 3: 1552.

[8] Azam, A. F., Ali, R. M. and Ali, K. 2008. "Ultrasound-Assisted Synthesis of Dentritic $\mathrm{ZnO}$
Nanostructure in Ionic Liquid." Materials Letters 62: 1789-92.

[9] Nandan, B., Venugopal, B., Amirthapandian, S., Panigrahi, B. K. and Thangadurai, P. 2013. "Effect of Pd Ion Doping in the Band Gap of $\mathrm{SnO}_{2}$ Nanoparticles." $J$ Nanopart Res 15: 1999.

[10] Tandon, S. P. and Gupta, J. P. 1970. "Measurement of Forbidden Energy Gap of Semiconductors by Diffuse Reflectance Technique.” Phys Status Solidi 38 (1): 363-7.

[11] Wu, J., Shin, H. and Wu, W. 2005. "Growth of $\mathrm{TiO}_{2}$ Nanorods by Two-Step Thermal Evaporation.” J. Vac. Sci. Technol. B 23: 2122.

[12] Wu, J.-M., Shin, H. and Wu, W.-T. 2006. "Formation and Photoluminescence of Single-Crystalline Rutile $\mathrm{TiO}_{2}$ Nanowires Synthesized by Thermal Evaporation." Nanotechnology 17: 105. 